A rare presentation of extrahepatic portal vein thrombosis, particularly with cavernomatous transformation, is biliary obstruction secondary to the cavernoma [1]. First-line therapy is currently biliary stenting, but disadvantages of this method are the requirement for repeated changing of the stents and stent-related complications [2-4].

A 45-year-old woman was referred to us with worsening jaundice and itching over a 12-month period. Her laboratory results included: bilirubin $82 \mu \mathrm{mol} / \mathrm{L}$, alkaline phosphatase (ALP) $1116 \mathrm{U} / \mathrm{L}$, gamma-glutamyl transferase (GGT) $1347 \mathrm{U} / \mathrm{L}$, aspartate aminotransferase (AST) $219 \mathrm{U} / \mathrm{L}$, alanine aminotransferase (ALT) $283 \mathrm{U} / \mathrm{L}$. Endoscopic retrograde cholangiopancreatography revealed common bile duct compression with mild intrahepatic duct dilatation (Figure $\mathbf{1}$ ), associated with an extrahepatic portal and splenic vein thrombosis with collaterals. A vascular hilar soft-tissue mass, surrounding both the common bile duct and a patent hepatic artery was confirmed by computed tomography and magnetic resonance imaging (MRI).

A transjugular intrahepatic portosystemic shunt (TIPS) procedure was planned in order to relieve the compression caused by the cavernoma. In order to decompress the biliary tree before we attempted the TIPS procedure, we inserted a $10-\mathrm{Fr} 120-$ $\mathrm{mm}$ common bile duct straight stent with side flaps (Diagmed Ltd., Thirsk, UK). The following day, the TIPS procedure was successfully performed, puncturing a patent intrahepatic portal vein branch.

The biliary stent was removed after 1 week. Fourteen months after the TIPS procedure the patient was asymptomatic, was not jaundiced, and showed the following laboratory results: bilirubin 14 $\mu \mathrm{mol} / \mathrm{L}$, ALP $456 \mathrm{U} / \mathrm{L}$, GGT $763 \mathrm{U} / \mathrm{L}$, ALT $167 \mathrm{U} / \mathrm{L}$. A follow-up magnetic resonance cholangiogram/MRI still showed the hilar

\title{
Relief of biliary obstruction due to portal vein cavernoma using a transjugular intrahepatic portosystemic shunt (TIPS) without the need for long-term stenting
}

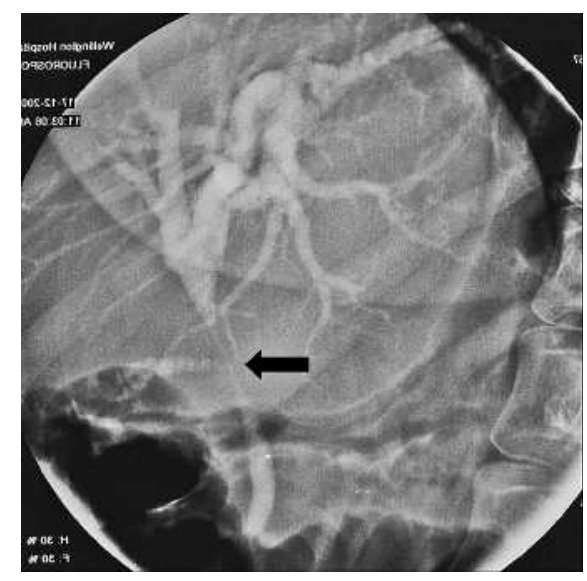

Figure 1 Endoscopic retrograde cholangiopancreatography showed dilatation of the intrahepatic biliary tree caused by a smooth common bile duct stricture (arrow) which had an appearance consistent with extrinsic compression.

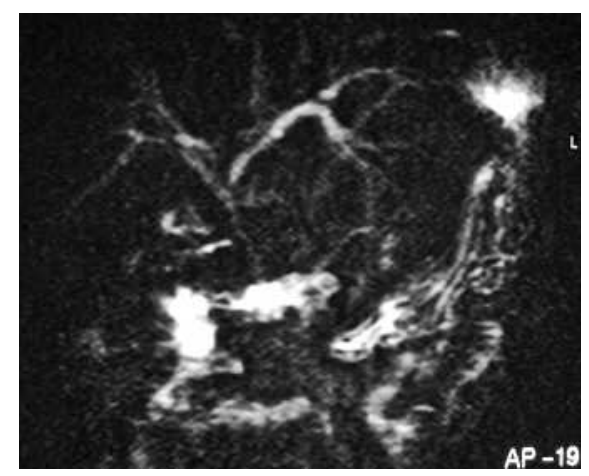

Figure 2 Follow-up breath-hold magnetic resonance cholangiopancreatogram showing only minor residual left intrahepatic duct dilatation.

mass, decreased in size, with only a slight residual dilatation of the left intrahepatic ducts (Figure 2). The patient remains on oral anticoagulation.

We believe that a TIPS procedure should be tried in symptomatic patients with biliary obstruction secondary to portal cavernoma/portal biliopathy. A common bile duct stent should be placed before attempting to decompress the biliary tree with a TIPS: if there is a technical failure of the TIPS, this at least provides symptomatic relief of itching and jaundice; if the TIPS is successful, the biliary stent can be removed.
Endoscopy_UCTN_Code_TTT_1AR_2AG

M. Senzolo', E. Cholongitas' ${ }^{1}$ J. Tibballs ${ }^{2}$, D. Patch ${ }^{1}$, C. K. Triantos ${ }^{1}$, D. Samonakis ${ }^{1}$, G. E. A. Bettany ${ }^{3}$, A. K. Burroughs ${ }^{1}$

${ }^{1}$ Liver Transplantation and Hepatobiliary Unit, Royal Free Hospital, London, United Kingdom

${ }^{2}$ Department of Radiology, Royal Free Hospital, London, United Kingdom

${ }^{3}$ King George Hospital, Ilford, United Kingdom

References

${ }^{1}$ Chandra R, Kapoor D, Tharakan A et al. Portal biliopathy. J Gastroenterol Hepatol 2001; 16: 1086-1092

${ }^{2}$ Khare R, Sikora SS, Srikanth G et al. Extrahepatic portal venous obstruction and obstructive jaundice: approach to management. J Gastroenterol Hepatol 2005; 20: 56-61

${ }^{3}$ Mutignani M, Shah SK, Bruni A et al. Endoscopic treatment of extrahepatic bile duct strictures in patients with portal biliopathy carries a high risk of haemobilia: report of 3 cases. Dig Liver Dis 2002; 34: 587 - 591

${ }^{4}$ Dumortier J, Vaillant E, Boillot O et al. Diagnosis and treatment of biliary obstruction caused by portal cavernoma. Endoscopy 2003; 35: 446-450

\section{Corresponding author}

\section{A. K. Burroughs, M.D.}

Liver Transplantation and

Hepatobiliary Unit

Royal Free Hospital

Pond Street

London NW3 2QG

United Kingdom

Fax: +44-020-7472-6226

E-mail:

Andrew.burroughs@royalfree.nhs.uk

Published online 6 June 2006 DOI: 10.1055/s-2006-944541 